Научная статья

УДК $330.15 ; 332.142 .6$

DOI: $10.17213 / 2075-2067-2021-5-77-85$

\title{
ПЕРСПЕКТИВЫ РАЗВИТИЯ ПРОМЫШЛЕННОГО РЕГИОНА В КОНТЕКСТЕ ЦЕЛЕЙ УСТОЙЧИВОГО РАЗВИТИЯ
}

\author{
Екатерина Олеговна Вегнер-Козлова \\ Институт экономики Уральского отделения Российской академии наук, \\ Екатеринбург, Россия \\ katya.human@mail.ru, ORCID: 0000-0003-4182-6514, AuthorID РИНЦ: 554997
}

\begin{abstract}
Аннотация. Целью исследования является оценка соответствия индустриальной экономики региона эколого-экономически сбалансированному типу развития в контексте иелей устойчивого развития.

Методологическую базу исследования представляют базисные положения кониепции устойчивого развития. К используемым научным методам относятся сравнительный, причинно-следственный и статистический анализ.

Результаты исследования. Глобальный тренд на устойчивое развитие привел к тому, что предпринимательский сектор с одной стороны сталкивается с рядом дополнительных требований и ограничений, однако одновременно получает новые конкурентные преимущества для долгосрочного стабильного развития. Особую актуальность задачи сочио-экологоэкономической устойчивости приобретают в промышленно-развитых регионах, где экономическая специфика обостряет проблематику негативного воздействия на окружаюшую среду. В работе проведен анализ показателей эко-интенсивности, позволяющих оценить переход региона к эколого-экономически сбалансированному типу развития. Показатели интенсивности загрязнения устанавливают корреляцию между эффективностью экономики и негативным воздействием экономической деятельности на окружаюшую среду. Снижение этого показателя возможно за счет внедрения «зеленых» технологий, ориентированных на устойчивый рост. Проведенный анализ позволяет предположсить, что для Свердловской области актуальными сферами для технологического «зеленого» развития могут стать технологии и производственные прочессы, способствующие снижению негативного воздействия на атмосферный воздух, сточные воды и объемы образования отходов.

Перспективы исследования заключаются в развитии направлений для перехода индустриального региона к принципам устойчивого развития.

Ключевые слова: экология, устойчивое развитие, индустриальные регионы, экоинтенсивность

Для цитирования: Вегнер-Козлова Е. О.Перспективы развития промышленного региона в контексте иелей устойчивого развития // Вестник Южно-Российского государственного технического университета. Серия: Социально-экономические науки. 2021. T. 14, №5. C. 77-85. http://dx.doi.org/10.17213/2075-2067-2021-5-77-85.
\end{abstract}

Благодарности: исследование выполнено в соответствии с государственным заданием для Института экономики УрО РАН.

(C) Вегнер-Козлова Е.О., 2021 
Original article

\title{
PROSPECTS FOR THE DEVELOPMENT OF THE INDUSTRIAL REGION IN THE CONTEXT OF THE SUSTAINABLE DEVELOPMENT GOALS
}

\author{
Ekaterina O. Wegner-Kozlova \\ Institute of Economics of the Ural branch of the Russian Academy of Sciences, \\ Yekaterinburg, Russia \\ katya.human@mail.ru,ORCID:0000-0003-4182-6514, AuthorID RSCI: 554997
}

\begin{abstract}
The purpose of the research is to assess the compliance of the industrial regional economy with an eco-economically balanced type of development in the context of the SDGs.

The methodological basis of the research is provided by the basic provisions of the concept of sustainable development. The scientific methods used include comparative causal and statistical analysis.

Research result. The global trend towards sustainable development has led to the fact that the business sector, on the one hand, faces a number of additional requirements and restrictions, but at the same time receives new competitive advantages for long-term stable development. The tasks of socio-ecological and economic sustainability are particularly relevant in industrialized regions, where economic specifics exacerbate the problems of negative impact on the environment. The article analyzes the eco-intensity indicators that allow us to assess the transition of the region to an eco-economically balanced type of development. Indicators of the intensity of pollution, establish a correlation between the efficiency of the economy and the negative impact of economic activity on the environment. The reduction of this indicator is possible due to the introduction of "green» technologies focused on sustainable growth. The analysis suggests that for the Sverdlovsk Region, technologies and production processes that contribute to reducing the negative impact on atmospheric air, wastewater and waste generation volumes can become relevant areas for technological «green» development.
\end{abstract}

The prospects of the research are to specify the directions for the transition of the industrial region to the principles of sustainable development.

Keywords: ecology, sustainable development, industrial regions, eco-intensity

For citation: Wegner-Kozlova E. O. Prospects for the development of the industrial region in the context of the sustainable development goals // Bulletin of the South Russian State Technical University. Series: Socio-economic Sciences. 2021; 14(5): 77-85. (In Russ.). http://dx.doi. org/10.17213/2075-2067-2021-5-77-85.

Acknowledgments: the research has been carried out in accordance with the state task for the Institute of Economics of the Ural Branch of the Russian Academy of Sciences.

Введение. Глобализация внесла свой вклад в изменение существующих систем международных взаимодействий и включила в них новые транснациональные акторы. После Конференции ООН по окружающей среде и развитию (ЮНСЕД) в 1992 г. в Риоде-Жанейро в качестве цели был поставлен переход к социоприродному устойчивому развитию (УР) как средству предотвращения экологической и других глобальных антропогенных катастроф и хаотической деградации [6].

В 2001 г. государства-члены ООН сформулировали основные цели развития тысячелетия (ЦРТ), достижение которых планировалось на 2015 г. и основная задача которых 
заключалась в том, чтобы способствовать ускорению развития беднейших наций. Общий вектор был задан в направлении индустриализации, экономического роста, развития научного и технического потенциала, ликвидации голода, болезней, неграмотности. По завершении периода, на который планировались ЦРТ, их логическим продолжением стала детерминация целей устойчивого развития (ЦУР).

В отличие от ЦРТ, ЦУР декларирует активное участие предпринимательства в процессе достижения устойчивости, что означает пересмотр принципов, стандартов, схем, и моделей ведения бизнеса для «участия в трансформационных процессах современного мира и подключения к формированию новой мировой повестки развития» $[1$, с. 41].

Ориентация предпринимательского сектора на ЦУР. Нацеленность на устойчивость становится конкурентным преимуществом, и, соответственно, ключевым элементом бизнес-стратегий. Предпринимательский сектор с одной стороны сталкивается с рядом дополнительных требований и ограничений, однако одновременно получает новые возможности и конкурентные преимущества для долгосрочного стабильного развития и соответствия ожиданиям стейкхолдеров.

Глобальный контекст ЦУР придает операционному ландшафту бизнеса новый облик, где требования к компаниям с точки зрения соответствия устойчивому развитию на международном, региональном и страновом уровнях растет. Если раньше бизнес рассматривал концепцию УР преимущественно в качестве «приятного дополнения» к основной деятельности и обеспечивал ее реализацию в рамках отдельных проектов, то теперь она становится центральным элементом бизнес-стратегий и ключевым ориентиром в повседневной деятельности [4].

По данным исследования Harvard Business School, компании с развитой культурой управления вопросами устойчивого развития показывают лучшие финансовые результаты по сравнению с компаниями с более низкой культурой управления вопросами устойчивого развития: более высокую доходность акций - 19,0\%/16,3\%, рентабельность капитала (ROE) - 16,6\%/13,1\% и рентабельность активов (ROA) $8,6 \% / 7,0 \%$. По данным исследования «Устойчивость глазами инвестора», проведенного Morgan Stanley Institute for Sustainable Investing, 72\% индивидуальных инвесторов уверены, что компаниям выгодно фокусироваться на устойчивости [5].

Актуальным для России примером является реализация механизма Трансграничного углеродного регулирования. В 2019 г. Россия подписала Парижское соглашение по климату, в соответствии с которым страны должны удержать рост глобальной средней температуры в пределах $1,5-2^{\circ} \mathrm{C}$ и сократить выбросы. Данное обстоятельство обостряет конкурентную борьбу внутри мирового энергетического рынка. В связи с этим становится очевидным: для РФ декарбонизация должна подразумевать структурную перестройку экономики с целью повышения ее эффективности при одновременном снижении углеродной нагрузки на экосистему, что сопряжено с технологическим развитием, внедрением инноваций, вопросами организационного и институционального характера, связанного с технологическим обновлением и перевооружением производств. В первую очередь, структурная перестройка должна затрагивать сектора промышленности (и не только непосредственно попадающие под трансграничное углеродное регулирование (металлургия, нефтегазодобыча и др.), но и машиностроительный сектор, приборостроение (в частности, производство средств экологического мониторинга)), транспортную отрасль, лесную отрасль, отрасль сельского хозяйства, финансовый сектор.

Таким образом, переход к устойчивому развитию требует с одной стороны от предпринимательства применения новых технологий, управленческих подходов, моделей и бизнес-практик, нацеленных на устойчивость. С другой стороны, органы исполнительной власти субъектов РФ и органы местного самоуправления должны учитывать ЦУР при разработке и реализации региональных программ экономического развития, планируя реальные инструменты содействия предпринимательскому сектору в подготовке к дополнительным требованиям, ограничениям и возможностям, обусловленным мировой тенденцией перехода к УР. 
Устойчивое развитие индустриальных регионов. Особую актуальность задачи социо-эколого-экономической устойчивости приобретают в промышленно-развитых регионах, где экономическая специфика обостряет проблематику негативного воздействия на ОС (табл. $\left.1^{1}\right)$.

Таким образом, для таких регионов важное значение приобретают ЦУР, направленные на охрану экосистем и снижение негативного воздействия на окружающую среду:

- ЦУР 12: обеспечение рациональных моделей потребления и производства;

- ЦУР 13: принятие срочных мер по борьбе с изменением климата и его последствиями;
- ЦУР 14: сохранение и рациональное использование океанов, морей и морских ресурсов в интересах устойчивого развития;

- ЦУР 15: защита, восстановление экосистем суши и содействие их рациональному использованию, рациональное управление лесами, борьба с опустыниванием, прекращение и обращение вспять процесса деградации земель и прекращение процесса утраты биологического разнообразия.

Мониторинг показателей достижения ЦУР осуществляется Росстатом, однако перечень национальных показателей достижения ЦУР не предполагает отражение региональной специфики. В связи с этим более репрезентативными представляются показатели

Таблица 1

Table 1

\section{Воздействие основных видов экономической деятельности на загрязнение окружающей среды в Свердловской области (по данным 2019 г.) \\ The impact of the main types of economic activity on environmental pollution in the Sverdlovsk region (according to 2019)}

\begin{tabular}{|c|c|c|c|}
\hline \multirow[b]{2}{*}{ Вид экономической деятельности } & \multicolumn{3}{|c|}{$\begin{array}{c}\text { Доля вида деятельности } \\
\text { в общем объеме загрязнения }\end{array}$} \\
\hline & $\begin{array}{c}\text { Водоотведение } \\
\text { в поверхностные } \\
\text { водные объекты } \\
\text { загрязненных } \\
\text { без очистки и } \\
\text { загрязненных } \\
\text { недостаточно } \\
\text { очищенных вод }\end{array}$ & $\begin{array}{c}\text { Использование } \\
\text { воды }\end{array}$ & $\begin{array}{l}\text { Образованные } \\
\text { отходы }\end{array}$ \\
\hline Добыча полезных ископаемых & $22,30 \%$ & $8,00 \%$ & $84,55 \%$ \\
\hline Обрабатывающие производства & $25,38 \%$ & $35,76 \%$ & $9,80 \%$ \\
\hline $\begin{array}{l}\text { Обеспечение электрической энергией, } \\
\text { газом, паром и кондиционирование } \\
\text { воздуха }\end{array}$ & $2,45 \%$ & $19,97 \%$ & $3,16 \%$ \\
\hline $\begin{array}{l}\text { Водоснабжение, водоотведение, орга- } \\
\text { низация сбора и утилизации отходов, } \\
\text { деятельность по ликвидации загряз- } \\
\text { нений }\end{array}$ & $48,40 \%$ & $32,40 \%$ & $1,21 \%$ \\
\hline $\begin{array}{l}\text { Прочие виды экономической деятель- } \\
\text { ности }\end{array}$ & $1,47 \%$ & $3,87 \%$ & $1,28 \%$ \\
\hline Всего по Свердловской области & $100,00 \%$ & $100,00 \%$ & $100,00 \%$ \\
\hline
\end{tabular}

1 Составлено автором по данным Государственного доклада «О состоянии и об охране окружающей среды Свердловской области в 2019 году». 
эко-интенсивности, позволяющие оценить переход региона к эколого-экономически сбалансированному типу развития [3]. Эко-интенсивность определяется как величина негативного воздействия на природные ресурсы и среды в расчете на единицу экономического результата и используется для оценки нагрузки антропогенной составляющей региона на его природную среду [2].

Рисунки 1-4 демонстрируют, что для Свердловской области характерно превышение показателей эко-интенсивности как над показателями по УрФО, так и над показателями по РФ по сбросу загрязненных сточных вод и выбросам в атмосферный воздух. Позитивная динамика в снижении экологической нагрузки наблюдается по показателю образования отходов производства и потребления.

Очевидно, что преодоление негативной нагрузки на ОС требует определённых затрат.

Положительная динамика расходов на охрану окружающей среды очевидна как

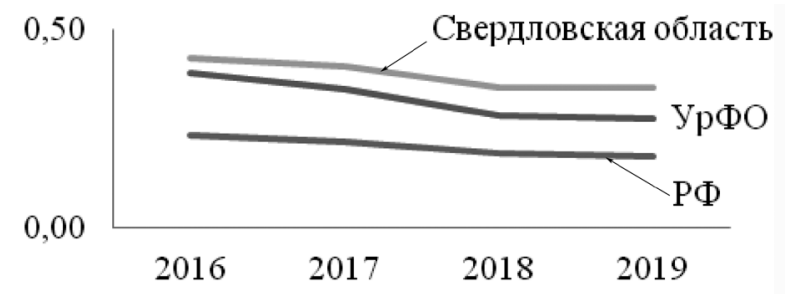

Рис. 1. Эко-интенсивность выбросов загрязняющих веществ в атмосферный воздух, т/млн. руб.

Fig. 1. Eco-intensity of emissions of pollutants into the atmospheric air, tons/million rubles

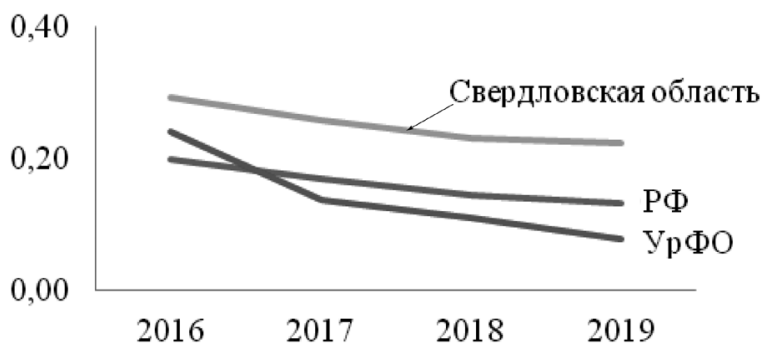

Рис. 3. Эко-интенсивность сброса загрязнённых сточных вод, м³/тыс. руб.

Fig. 3. Eco-intensity of discharge of polluted wastewater, $\mathrm{m}^{3} /$ thousand rubles для РФ, так и для Свердловской области. Снижение инвестиций в основной капитал направленных на охрану окружающей среды наблюдается по УрФО (табл. 2).

Все рассматриваемые показатели расходов на охрану окружающей среды тесно взаимосвязаны с показателями ВРП по РФ в целом. По Свердловской области тесная взаимосвязь величины ВРП с расходами на охрану окружающей среды и с инвестициями в основной капитал, направленными на охрану окружающей среды (табл. 3).

Проведенный анализ позволяет предположить недостаточную заинтересованность предпринимательского сегмента в достижении устойчивости. Несмотря на тенденцию к снижению эко-интенсивности по выбросам загрязняющих веществ в атмосферный воздух и по сбросу загрязнённых сточных вод, показатели Свердловской области превышают оценку как по УрФО, так и по РФ в целом. Напряженной остается интенсивность

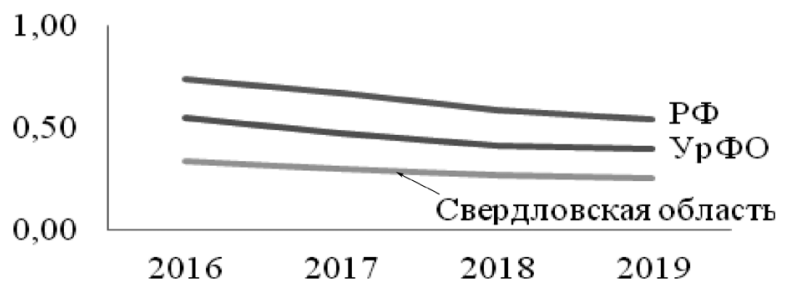

Рис. 2. Эко-интенсивность использования свежей воды, м ${ }^{3} /$ тыс.руб.

Fig. 2. Eco-intensity of fresh water use, $\mathrm{m}^{3} /$ thousand rubles

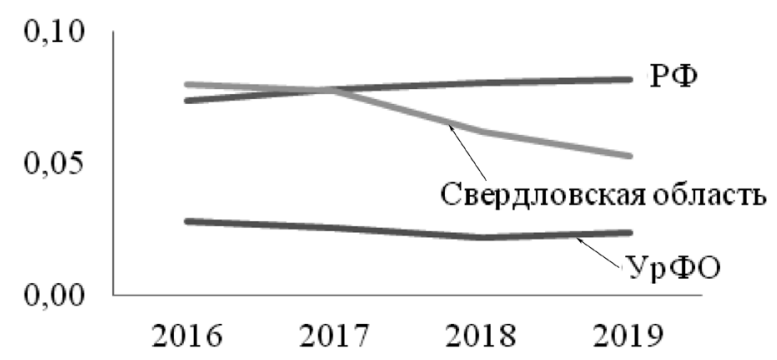

Рис. 4. Эко-интенсивность образования отходов производства и потребления, т/тыс. руб.

Fig. 4. Eco-intensity of production and consumption waste generation, tons/thousand rubles 


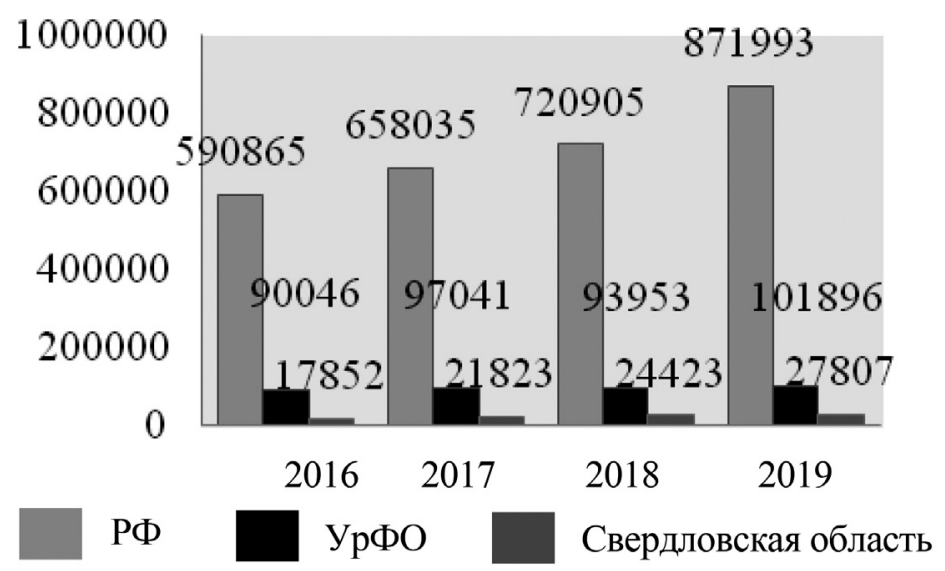

Рис. 5. Расходы на охрану окружающей среды, млн. руб.

Fig. 5. Environmental protection costs, million rubles

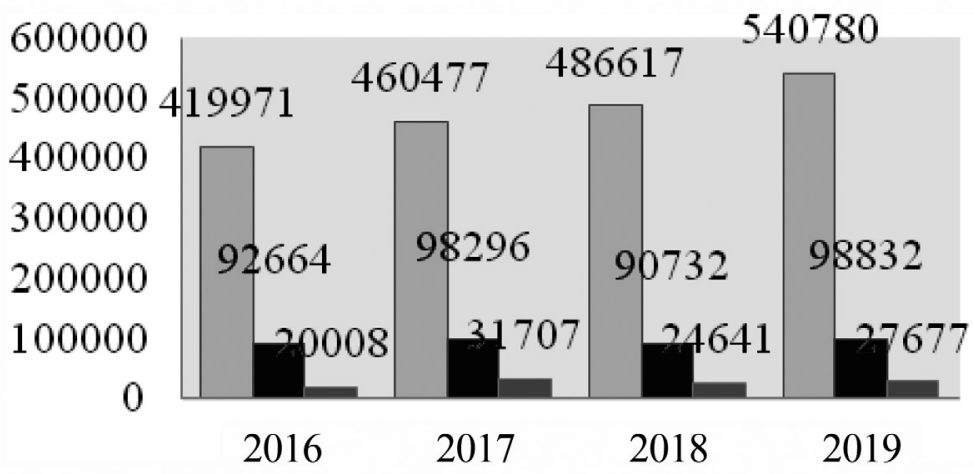

РФ $\square$ УрФО $\square$ Свердловская область

Рис. 6. Текущие (эксплуатационные) затраты на охрану окружающей среды, млн. руб.

Fig. 6. Current (operational) costs for environmental protection, mln. rubles

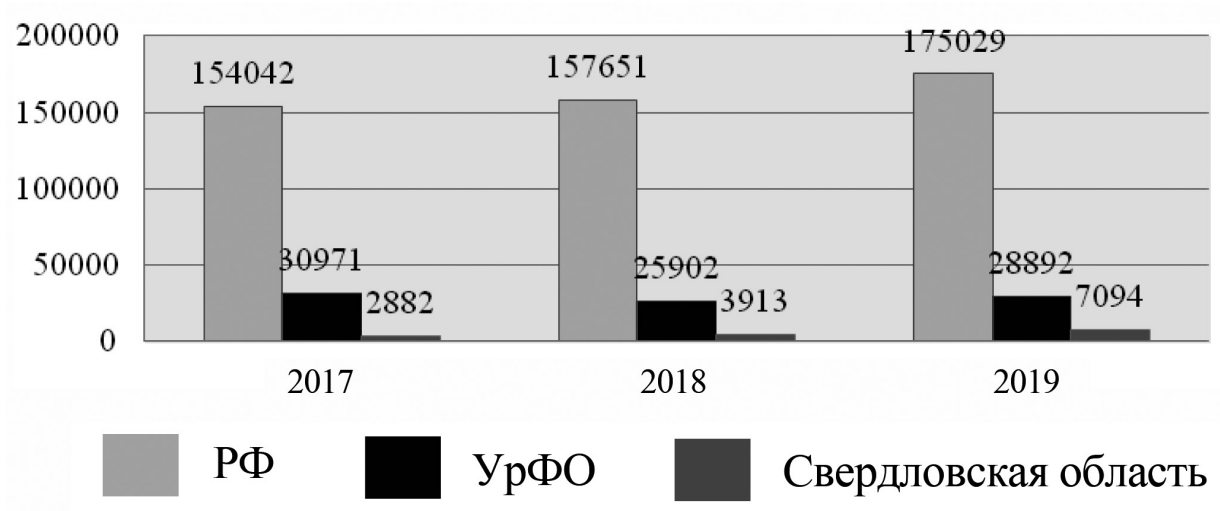

Рис. 7. Инвестиции в основной капитал, направленные на охрану окружающей среды и рациональное использование природных ресурсов, млн. руб.

Fig. 7. Investments in fixed assets aimed at environmental protection and rational use of natural resources, million rubles 
образования отходов производства и потребления. Высокие показатели эко-интенсивности свидетельствуют, прежде всего, о низком уровне технической оснащенности предприятий, что позволяет выделить данные направления в качестве приоритетных для технологического развития.

Заключение. Эко-интенсивность позволяет оценить соотношение эффективности хозяйственной деятельности с уровнем ее воздействия на окружающую среду. Показатель интенсивности загрязнения устанавливает корреляцию между эффективностью экономики и негативным воздействием экономической деятельности на окружающую среду. Снижение этого показателя возможно за счет внедрения «зеленых» технологий, ориентированных на устойчивый рост. Для координации экономического развития необ- ходимо учитывать региональные особенности, что повышает эффективность принимаемых управленческих мер. В частности, для Свердловской области актуальными сферами для технологического «зеленого» развития могут стать технологии и производственные процессы, способствующие снижению негативного воздействия на атмосферный воздух, сточные воды и объемы образования отходов. В первую очередь, это касается целенаправленного развития сегмента высокотехнологичного, наукоемкого малого предпринимательства и развития цифровизации и ІоТ-технологий в области мониторинга окружающей среды, позволяющего осуществлять оперативный сбор и анализ данных о воздействии на окружающую среду, предотвращать экологические аварии и катастрофы и более эффективно осуществлять принятие управленческих решений на всех уровнях.

Таблица 2

Table 2

\section{Динамика расходов на охрану окружающей среды Dynamics of environmental protection expenditures}

\begin{tabular}{|l|c|c|c|}
\hline & $\begin{array}{c}\text { Темп роста } \\
\text { расходов на охрану } \\
\text { окружающей среды, } \\
2019 / 2016\end{array}$ & $\begin{array}{c}\text { Темп роста текущих } \\
\text { затрат на охрану } \\
\text { окружающей среды, } \\
2019 / 2016\end{array}$ & $\begin{array}{c}\text { Темп роста инвестиций в ОК, } \\
\text { направленных на охрану } \\
\text { окружающей среды, } \\
2019 / 2017\end{array}$ \\
\hline РФ & $147,60 \%$ & $128,80 \%$ & $113,60 \%$ \\
\hline УрФО & $113,20 \%$ & $106,70 \%$ & $93,30 \%$ \\
\hline $\begin{array}{l}\text { Свердловская } \\
\text { область }\end{array}$ & $155,80 \%$ & $138,30 \%$ & $246,10 \%$ \\
\hline
\end{tabular}

Таблица 3

Table 3

Коэффициент корреляции показателей с величиной ВРП The coefficient of correlation of indicators with the value of GRP

\begin{tabular}{|l|c|c|c|}
\hline & $\begin{array}{c}\text { Расходы на охрану } \\
\text { окружаюей среды }\end{array}$ & $\begin{array}{c}\text { Текущие затраты } \\
\text { на охрану } \\
\text { окружающей среды } \\
\text { направленные на охрану } \\
\text { окружающей среды и } \\
\text { рациональное использование } \\
\text { природных ресурсов }\end{array}$ \\
\hline РФ & 0,94 & 0,96 & 0,84 \\
\hline УрФО & 0,68 & 0,11 & $-0,76$ \\
\hline $\begin{array}{l}\text { Свердловская } \\
\text { область }\end{array}$ & 0,99 & 0,41 & 0,92 \\
\hline
\end{tabular}




\section{Список источников}

1. Бакушев В.В., Понеделков А.В., Моисеев В.Н. «Устойчивое развитие с частным сектором» — мировое целеполагание для бизнеса и политиков до 2030 года // Наука и образование: хозяйство и экономика; предпринимательство; право и управление. 2016. №4 (71). С. 40-45.

2. Глазырина И.П., Забелина И.А., Клевакина Е.А. Экологическая составляющая экономического развития: приграничные регионы России и Китая // Всероссийский экономический журнал ЭКО. 2014. №6. С. 5-24.

3. Дьяков М.Ю. Эко-интенсивность экономики Камчатского края как индикатор перехода к эколого-экономической сбалансированности // Всероссийский экономический журнал ЭКО. 2015. №12 (498). С. 154-164.

4. Новак К., Зайцева Н. Переворот устойчивости [Электронный ресурс] // BRICS Business magazine. 2015. №1. URL: https:// bricsmagazine.com/ru/articles/perevorotustoychivosti (дата обращения: 01.07.2021).

5. Судас Л.Г. Бизнес за устойчивое развитие // Государственное управление. Электронный вестник. 2017. №64. С. 241-262.

6. Урсул А.Д. Становление устойчивой цивилизации: новые глобальные цели // Философия и общество. 2016. №1. С. 29-56.

\section{References}

1. Bakushev V.V., Ponedelkov A.V., Moiseev V.N. «Ustojchivoe razvitie s chastnym sektorom» - mirovoe celepolaganie dlja biznesa i politikov do 2030 goda [«Sustainable development with the private sector» - Global goalsetting for business and politicians until 2030].
Nauka i obrazovanie: hozjajstvo i jekonomika; predprinimatel'stvo; pravo i upravlenie [Science and education: farm and economics; entrepreneurship; Right and management]. 2016; 4 (71): 40-45. (In Russ.).

2. Glazyrina I.P., Zabelina I.A., Klevakina E.A. Jekologicheskaja sostavljajushhaja jekonomicheskogo razvitija: prigranichnye regiony Rossii i Kitaja [Environmental component of economic development: the border regions of Russia and China]. Vserossijskij jekonomicheskij zhurnal JeKO [National Economic Journal ECO]. 2014; 6: 5-24. (In Russ.).

3. D'jakov M. Ju. Jeko-intensivnost' jekonomiki Kamchatskogo kraja kak indikator perehoda $\mathrm{k}$ jekologo-jekonomicheskoj sbalansirovannosti [Eco-intensity of the economy of the Kamchatka Territory as an indicator of the transition to ecological and economic balance]. Vserossijskij jekonomicheskij zhurnal JeKO [National Economic Journal ECO]. 2015; 12 (498): 154-164. (In Russ.).

4. Novak K., Zajceva N. Perevorot ustojchivosti [Sustainability turnover] [Jelektronnyj resurs] // BRICS Business magazine. 2015; 1. URL: https://bricsmagazine.com/ru/articles/perevorot-ustoychivosti (date accessed: 01.07.2021). (In Russ.).

5. Sudas L. G. Biznes za ustojchivoe razvitie [Business for Sustainable Development]. Gosudarstvennoe upravlenie. Jelektronnyj vestnik [Public administration. Electronic bulletin]. 2017; 64: 241-262. (In Russ.).

6. Ursul A.D. Stanovlenie ustojchivoj civilizacii: novye global'nye celi [The formation of a sustainable civilization: new global goals]. Filosofija $i$ obshhestvo [Philosophy and Society]. 2016; 1: 29-56. (In Russ.).

Статья поступила в редакцию 06.09.2021; одобрена после рецензирования 18.09.2021; принята к публикащии 21.09.2021.

The article was submitted on 06.09.2021; approved after reviewing on 18.09.2021; accepted for publication on 21.09.2021. 


\section{ИНФОРМАЦИЯ ОБ АВТОРАХ}

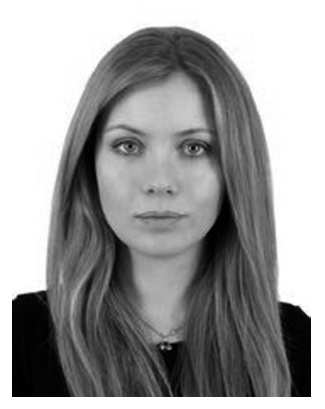

Вегнер-Козлова Екатерина Олеговна - кандидат экономических наук, научный сотрудник Института экономики Уральского отделения Российской академии наук, Уральский федеральный университет имени первого Президента России Б.Н. Ельцина.

Россия, г. Екатеринбург, ул. Ленина, 136

Ekaterina O. Wegner-Kozlova - Candidate of Economic Sciences, Research Associate, Institute of Economics of the Ural branch of the Russian Academy of Sciences, Ural Federal University named after the first President of Russia B. N. Yeltsin.

$13 b$ Lenina st., Yekaterinburg, Russia 